\title{
The Use of Neoprene in Experimental Pancreatitis
}

\author{
ALEXANDRU GRIGOROVICl ${ }^{1}$, CRISTIAN VELICESCU ${ }^{1 *}$, DELIA HINGANU2*, ALINA CALIN ${ }^{3}$, MARIUS VALERIU HINGANU2*, \\ DAN ANDRONIC ${ }^{1}$ \\ ${ }^{1}$ Grigore T. Popa University of Medicine and Pharmacy, Faculty of Medicine, It Surgical Department, 16 Universitatii Str., 700115, \\ Iasi, Romania \\ ${ }^{2}$ Grigore T. Popa University of Medicine and Pharmacy, Faculty of Medicine, I st Morpho-Functional Sciences Department, \\ 16 Universitatii Str., 700115, Iasi, Romania \\ ${ }^{3}$ St. Spiridon Emergency Clinical Hospital, $4{ }^{\text {rd }}$ Surgery Clinic, 1 Independentei Blvd., Iasi, Romania
}

\begin{abstract}
The concept of chronic pancreatitis has been stated in our country much later than acute pancreatitis. This manuscript proposes a synthesis of the etiopathogenic, diagnostic and therapeutic data in chronic pancreatitis based on actual information correlated with the results of our experimental study. The experiment was conducted on 18 animals, in which was performed the intraduodenal ligation of the pancreatic duct apertures and the obstruction of the pancreatic ducts with intraparenchymatous, intraoperative neoprene injections. We investigated the lesions by using intraoperative pancreatic tissue collected after injections. The results encourage us to continue the research and to choose genetically modified animals because are closer to the human one.
\end{abstract}

Keywords: chronic pancreatitis, acute pancreatitis, expeimental model, neoprene

The concept of chronic pancreatitis has been stated in our country much later than acute pancreatitis. Gastroenterologists and, in particular, surgeons discuss less about this disease, which exists and will likely exist as long as alcohol consumption is maintained at a high level.

The individualisation of chronic pancreatic condition was first observed by anatomopathologists and surgeons, and more late it was achieved the clinical and morphopathological integration of the disease.

Chronic pancreatitis is defined by morphological criteria (inflammatory disease characterized by irreversibility of morphological lesions), clinical (presence of pancreatic pain syndrome) and functional (progressive deterioration of functional ability of the organ) [1].

This manuscript proposes a synthesis of the etiopathogenic, diagnostic and therapeutic data in chronic pancreatitis based on actual information correlated with the results of our experimental study.

Pancreatitis classification of Marseilles in 1988 gives a relatively current view of the inflammatory pathology of the pancreas [2]. Thus, pancreatitis is divided into acute pancreatitis that is not defined as a disease but only as a group of lesions that can affect the pancreas or peripancreatic tissues. These include edema, adipose necrosis or haemorrhagic necrosis. These injuries are generally reversible except in rare cases, where necrosis is followed by a stenosis of pancreatic canals that will cause obstructive chronic pancreatitis above the obstruction. Pancreatic haemorrhagic necrosis is mostly peripancreatic, can increase in volume and be the origin of necrotic pseudocysts limited by fibrosis to neighboring organs. Infection of pseudocystis gives rise to abscesses. Pseudocysts are the most common cause of rare stenosis of pancreatic canal.

Acute pancreatitis are of various extrapancreatic causes, such as: biliary lithiasis, surgical or abdominal trauma, medications, papillary endoscopic catheterization $[3,4]$. Intrapancreatic causes include: pancreatic cancer and especially chronic pancreatitis that complicates at the beginning with acinar necrosis.

Chronic pancreatitis is characterized by fibrosis, loss of exocrine parenchyma, then endocrine and canalicular lesions.

Research into the pathogenesis and treatment of pancreatitis faces many obstacles due to the difficult anatomical approach of this organ and also due to a difficult clinical prognosis [5]. Most current knowledge about pancreatitis is based on research on experimental animals models [6].

Experimental models of chronic pancreatitis aim to reproduce morphopathological changes: cell loss, chronic inflammatory infiltration, formation of intraductal protein obstructions, calcification and fibrosis. Despite the effort to clarify the pathogenesis and natural evolution of chronic pancreatitis, a relevant and satisfactory experimental model has not yet been established [7].

\section{Experimental part}

Materials and methods

Our study was conducted in the experimental laboratory of the 3rd Surgery Clinic, in Iasi, within the concerns about the etiopathogenesis and treatment of chronic pancreatitis. It have been developed an experimental model to produce this disease in dogs.

The experiment was performed on 18 dogs, in which the intraduodenal ligation of the pancreatic duct apertures was performed in two cases and the obstruction of the pancreatic ducts by intraparenchymatous, intraoperative neoprene injections in the other 16 cases.

The experimental study respects the principles of the Helsinki Declaration on Animal Rights.

\section{Results and discussions}

We investigated the lesions through intraoperative pancreatic tissue collected at 2- 3 week intervals, 3-6 months and at necropsy. 
Monitoring of glycemia was done weekly by observing and noting its variations. It was demonstrated the integrity of the Langerhans islands, with moderate decrease of their volume.

At the time when acinar tissue sclerosis was obtained, six months after neoprene injection, pancreas with chronic lesions was transplantated to a pancreatectomized animal. The pancreas was heterotopically fixed in the right iliac fossa at the spleen vessels.

It have been observed aspects regarding the pathogenesis, clinical, evolution and treatment of chronic pancreatitis compared to acute pancreatitis.

Experimentally induced pancreatitis in rats using cerulein is the most commonly used experimental animal model of acute pancreatitis. The benefits of this model are reproducibility and the fact that it is economical $[8,9]$.

The acute pancreatitis model induced with bile salts was accepted as a representative model for severe acute pancreatitis with pancreatic necrosis $[10,11]$. The experiment is performed by injecting the substance through the canalicular opening and infusing 0.2 to 0.3 $\mathrm{mL}$ of $3 \%$ to $5 \%$ sodium taurocholate in a retrograde way. Among the difficulties in achieving this model are the abdominal incision and the experience required to introduce the cannula through the opening of the pancreatic duct. This experimental model induces severe hemorrhagic necrosis of the pancreas in a relatively short period with the appearance of nonuniform pancreatic lesions.

Another model of experimental induction of acute pancreatitis is that of choline-deficient diet supplemented with ethion. The induction of acute hemorrhagic pancreatitis occurs in about 5-10 days. The main disadvantage of this model is given by the occurrence of acute pancreatitis that appear only in young female mice [12].

Acute necrotizing pancreatitis model induced by Larginine is achieved by a single intraperitoneal injection with an excessive dose [13].

Changes observed in the pancreas after ligation of the pancreatic duct vary with the animals used and simulate that the ampulle is obstructed by a bile stone. Bile salts replenish in the pancreatic duct and induce acute pancreatitis. Since the pressure in the pancreatic duct is greater than in the bile duct, it is known that pancreatic juice refills in the bile ducts only in the presence of obstruction with a large orifice and not vice versa. Pancreatic inflammatory response rarely occurs in patients with Vater ampoule cancer, even after the pancreatic duct has been obstructed by the tumor, which makes the validity of this hypothesis questionable [14, 15].

If the pancreatic duct is ligated in rats, initial morphopathological manifestations such as pancreatic edema, infiltration of inflammatory cells, hyperamylase are compatible with acute pancreatitis, which lead to chronic pancreatitis over time. Thus, injuries such as atrophy in acinar cells and fibrosis will occur $[16,17]$.

Of the various experimental models of chronic pancreatitis, the most commonly used are surgical ligation of the pancreatic duct (obstructive), ethanol intake, repeat injection of cerulein, and toxic-induced models.

The obstructive model is based on the ligation of the pancreatic duct and induces glandular fibrosis. Clinical and pathological manifestations after canal ligation are dependent on the species and type of animal used.
Thus, in rats the ligation results in cellular atrophy and fibrosis, without a marked inflammatory reaction, and in mice induces a uniform fibrosis. In these situations, duct hypertension suggests that pancreatic duct hypertension contributes to the initiation and development of chronic pancreatitis [18].

The model realised by repeated administration of cerulein induces recurrent acute pancreatitis episodes leading to chronic lesions [19]

Experimentally, alcohol intake did not cause chronic pancreatitis despite the long duration of the experiments. On the other hand, the combination of alcohol and other toxic agents, such as cerulein or lipopolysaccharide, leads to the occurrence of pancreatic fibrosis [20].

Toxic induced pancreatitis by administration of dibuthyddine dichloride is used to induce chronic pancreatic lesions of the edematous type [21].

The use of L-arginine in the induction of chronic pancreatitis leads to the appearance of a severe necrotic form, causing progressive degeneration of the pancreas. Even though this experimental model is simple to perform and has features similar to human lesions, their histological appearance differs by progressive replacement of adipose tissue [22].

Time obsevation of animals with endocrine pancreas transplanted has been demonstrated the effectiveness of complete destruction of external neoprene secretion, at the same time preserving internal function, Langerhans Islands remaining functional. Unlike dogs, in rodents, pancreatic exocrine function shows a significant decrease 2 weeks after duct ligation. The method of maintaining the pancreas with intense lesions of chronic pancreatitis without secretory activity by blocking with inactive substances such as latex or neoprene can still be an alternative.

Pancreas transplantation with chronic pancreatitis experimentally induced in the iliac vessels of the beneficiary produces an important surgery trauma, in cases where either a triple Salambier derivation or a resectional cephalic process is used, on a pancreas that also exhibits body-caudal lesions.

Most experimental studies on dogs are those based on pancreatic and/or alcoholic toxic diets. Induction of a chronic pancreatic reaction by obliteration of neoprene pancreatic ducts produces morphopathological manifestations close to human ones at a low cost in a relatively short period of time but does not affect endocrine function as well.

\section{Conclusions}

Each experimental model has its own advantages or disadvantages. In spite of research in the field, there are still many questions to be solved. The results encourage us to continue the research and to choose genetically modified animals because are closer to the human one.

\section{Referrences}

1.HUE SU, K.,, CUTHBERTSON, C., CHRISTOPHI, C. HPB (Oxford) 8, no.4, 2006, p. 264.

2.SINGER, M.V., CYR, K., SARLES, H. Revised classification of pancreatihs.Report of the Second International Symposium on the Classification of Pancreatitis in Marseille, France, March 29-30, 1984. Gastroenterology, 89, no.3, 1985, p. 683.

3.HINGANU, M.V., SALAHORU, P., HINGANU, D. Rev Med Chir Soc Med Nat lasi, 122, no.3, 2018, p. 522. 
4.GATU, A., VELICESCU, C., GRIGOROVICI, A., DANILA, R., MUNTEAN, V., MOGOS, S.J., MOGOS, V., VULPOI, C., PREDA, C., BRANISTEANU, D. ACTA ENDOCRINOLOGICA-BUCHAREST. 13, no.4, 2017, p.441. 5.SCUTARIU, M.M., HINGANU, D., MACOVEI, G., HINGANU, M.V. ROMANIAN JOURNAL OF ORAL REHABILITATION, 10, no.4, 2018, p.186.

6.JIN HYUN, J., SIK LEE, H., Clin Endosc., 47, no.3, 2014, p. 212.

7.AGHDASSI, A.A., MAYERLE, J., CHRISTOCHOWITZ, S., WEISS, F.U., SENDLER, M., LERCH, M.M. Fibrogenesis Tissue Repair., 4, 2011, p. 26.

8.LAMPEL, M., KERN, H.F. Virchows Arch A Pathol Anat Histol., 373, 1977, p.97.

9.SALUJ A, A., SAITO, I., SALUJA, M., et al. Am J Physiol., 249, no.6, 1985, p. 702.

10.AHO, H.J., AHOLA, R.A., TOLVANEN, A.M., NEVALAINEN, T.J. Res Exp Med, 182, 1983, p. 79.

11.AHO, H.J., KOSKENSALO, S.M., NEVALAINEN, T.J. Scand J Gastroenterol, 15, 1980, p. 411.

12.LOMBARDI, B., ESTES, L.W., LONGNECKER, D.S. Am J Pathol, 79, 1975, p.465.

13.TANI, S., ITOH, H., OKABAYASHI, Y., et al. Dig Dis Sci., 35, 1990, p. 367.
14.STEER, M.L. Etiology and pathophysiology of acute pancreatitis. In: Go VL, DiMagno EP, Gardner JD, Lebenthal E, Reber HA, Scheele GA, editors. The Pancreas: Biology, Pathobiology, and Disease. 2nd ed. New York: Raven; 1993. p. 581-592.

15.LERCH, M.M., GORELICK, F.S. Models of acute and chronic pancreatitis. Gastroenterology. 2013;144:1180-1193.

16.OHSHIO, G., SALUJA, A., STEER, M.L. Gastroenterology, 100, 1991, p. 196.

17.WATANABE, S., ABE, K., ANBO, Y., KATOH, H. Arch Histol Cytol., 58, 1995, 365.

18.YAMAMOTO, M., OTANI, M., OTSUKI, M. Am J Physiol Gastrointest Liver Physiol., 291, 2006, p. 700.

19.NEUSCHWANDER-TETRI, B.A., BRIDLE, K.R., WELLS, L.D., MARCU, M., RAMM, G.A. Lab Invest., 80, 2000, p.143.

20.VONLAUFEN, A., XU, Z., DANIEL, B., et al. Gastroenterology., 133, 2007, p.129.

21.SPARMANN, G., MERKORD, J ., J ÄSCHKE, A., et al. Gastroenterology., 112, 1997, p. 1664

22.WEAVER, C., BISHOP, A.E., POLAK, J.M. Exp Mol Pathol., 60, 1994, p.71.

$\overline{\text { Manuscript received: } 21.07 .2018}$ 